\title{
Synthesis and Physico-chemical studies of a new non-centrosymmetric organic-inorganic hybrid material: $\left[2,3-\left(\mathrm{CH}_{3}\right)_{2} \mathrm{C}_{6} \mathrm{H}_{3} \mathrm{NH}_{3}\right]_{4}$ $\mathrm{BiBr}_{6} \mathrm{NO}_{3} \cdot 2 \mathrm{H}_{2} \mathrm{O}$
}

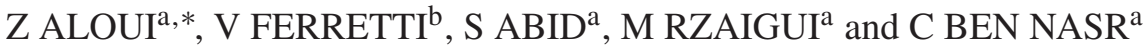 \\ ${ }^{a}$ Laboratoire de Chimie des Matériaux, Faculté des Sciences de Bizerte, Université de Carthage, \\ Zarzouna 7021, Tunisie \\ ${ }^{b}$ Department of Chemical and Pharmaceutical Sciences and Center for Structural Diffractometry, \\ via Fossato di Mortara 17, I-44121 Ferrara, Italy \\ e-mail: aloui_zouhaier@yahoo.fr
}

MS received 8 May 2014; revised 11 June 2014; accepted 29 June 2014

\begin{abstract}
Organic-inorganic hybrid single crystals of $\left[2,3-\left(\mathrm{CH}_{3}\right)_{2} \mathrm{C}_{6} \mathrm{H}_{3} \mathrm{NH}_{3}\right]_{4} \mathrm{BiBr}_{6} \mathrm{NO}_{3} .2 \mathrm{H}_{2} \mathrm{O}$ were obtained by slow evaporation at room temperature and characterized by X-ray diffraction, IR and solid state NMR. This compound crystallizes in orthorhombic non-centrosymmetric space group Pca $2_{1}$ with the following lattice parameters: $\mathrm{a}=25.8217(1), \mathrm{b}=7.8909(2), \mathrm{c}=21.4328(3) \AA, \mathrm{V}=4367.07(13) \AA^{3}$ and $\mathrm{Z}=4$. The structure was refined to $\mathrm{R}=0.057$ for 7069 independent reflections. The crystal is built up of 2,3-dimethylanilinium cations, $\left[\mathrm{BiBr}_{6}\right]^{3-}$, disordered $\left[\mathrm{NO}_{3}\right]$ anions and water molecules. The crystal packing is governed by a threedimensional network of O-H... O, N-H... O and N-H... Br hydrogen bonds and van der Waals interaction. The infrared spectrum has been interpreted on the basis of literature data. Solid state ${ }^{13} \mathrm{C} C \mathrm{CP}-\mathrm{MAS}-\mathrm{NMR}$ spectrum is in agreement with the $\mathrm{X}$-ray structure.
\end{abstract}

Keywords. Hybrid material; X-ray diffraction; hydrogen bonds; infrared spectroscopy; NMR spectroscopy.

\section{Introduction}

For the past three decades, the fields of fibre electronics, optical communication and lasers have experienced tremendous advancements. Non-linear optical (NLO) materials have received much attention due to their applications in optical data storage, electro-optical shutters, colour displays, optical communication and signal processing. ${ }^{1}$

Inorganic NLO materials exhibit excellent mechanical and thermal properties ${ }^{2-5}$ but possess relatively modest optical non-linearities because of the lack of extended $\pi$-electron delocalization. Currently, these hybrid materials are gaining attention because they share the properties of both organic and inorganic materials, such as higher second order optical non-linearities and stable physico-chemical performance.

Among the extensively studied halometalate hybrids, the halobismuthate (III) family, and in particular the bromobismuthate, is composed of isolated distorted $\left[\mathrm{BiBr}_{6}\right]^{3-}$ octahedra or connected by corners, edges, or faces forming one-dimensional chains, or, two threedimensional framework. ${ }^{6,7}$ In the majority of these hybrid materials the anionic moieties are rigid, whereas

\footnotetext{
*For correspondence
}

the organic cations are placed in large cavities of the anionic substructure through hydrogen bonds and electrostatic interactions. In addition, the occurrence of cation-anion interaction, usually of the type $\mathrm{N}$ $\mathrm{H}_{\text {cation }} \ldots \mathrm{X}_{\text {anion }}{ }^{8}$ influences the crystal packing

In this paper, we report a new inorganic-organic hybrid compound, [2,3- $\left.\left(\mathrm{CH}_{3}\right)_{2} \mathrm{C}_{6} \mathrm{H}_{3} \mathrm{NH}_{3}\right]_{4} \mathrm{BiBr}_{6} \mathrm{NO}_{3}$. $2 \mathrm{H}_{2} \mathrm{O}$, possessing a zero-dimensional structure. This material crystallizes in a non-centrosymmetric space group and could be a good candidate for non-linear optical applications. In addition, the vibrational and solid state ${ }^{13} \mathrm{C}$ MAS NMR spectrum of the material is reported.

\section{Experimental}

\subsection{Synthesis}

For the preparation of the title compound, concentrated hydrobromic acid, $48 \%$ purity, was added dropwise to a mixture of 2,3-dimethylaniline and ethanol until complete dissolution of the solid phase. Similarly, concentrated hydrobromic acid was added dropwise to dissolve the solid phase persisting in a mixture of bismuth nitrate pentahydrate and water. The two solutions were 
mixed and stirred for $30 \mathrm{~min}$. The resulting precipitate was filtered off and dissolved in hydrobromic acid. Pale yellow crystals suitable for X-ray analysis were obtained after several weeks by slow evaporation of the solvent at room temperature.

\subsection{Physical measurements}

The infrared spectrum was recorded in the range of $4000-400 \mathrm{~cm}^{-1}$ with a Perkin-Elmer 1000 FTIR spectrometer using a sample dispersed in spectroscopically pure $\mathrm{KBr}$ pressed into a pellet.

Table 1. Crystal data and structure refinement for [2,3$\left.\left(\mathrm{CH}_{3}\right)_{2} \mathrm{C}_{6} \mathrm{H}_{3} \mathrm{NH}_{3}\right]_{4} \mathrm{BiBr}_{6} \mathrm{NO}_{3} .2 \mathrm{H}_{2} \mathrm{O}$.

\begin{tabular}{|c|c|}
\hline Chemical formula & $4\left(\mathrm{C}_{8} \mathrm{H}_{12} \mathrm{~N}\right) \cdot \mathrm{BiBr}_{6} \cdot \mathrm{NO}_{3} \cdot 2\left(\mathrm{H}_{2} \mathrm{O}\right)$ \\
\hline $\mathrm{M}_{\mathrm{r}}$ & 1275.23 \\
\hline $\begin{array}{l}\text { Crystal system, } \\
\text { space group }\end{array}$ & Orthorhombic, $P c a 2_{1}$ \\
\hline $\mathrm{a}, \mathrm{b}, \mathrm{c}(\AA)$ & $\begin{array}{l}25.8217(1), 7.8909(2), \\
21.4328(3)\end{array}$ \\
\hline $\mathrm{V}\left(\AA^{3}\right)$ & $4367.07(13)$ \\
\hline $\mathrm{Z}$ & 4 \\
\hline Radiation type & Mo $K \alpha$ \\
\hline$\mu\left(\mathrm{mm}^{-1}\right)$ & 9.57 \\
\hline Crystal size (mm) & $0.49 \times 0.17 \times 0.15$ \\
\hline $\begin{array}{l}\text { No. of measured, indepen- } \\
\text { dent and observed } \\
{[I>2 \mathrm{~s}(I)] \text { reflections }}\end{array}$ & $39634,9180,7906$ \\
\hline $\mathrm{R}_{\text {int }}$ & 0.098 \\
\hline$R\left[F^{2}>2 \mathrm{~s}\left(F^{2}\right)\right], w R\left(F^{2}\right), S$ & $0.057,0.159,1.04$ \\
\hline $\begin{array}{l}\text { No. of reflections/ } \\
\text { No. of parameters }\end{array}$ & $9180 / 440$ \\
\hline$\Delta \rho_{\max }, \Delta \rho_{\min }\left(\mathrm{e} \AA^{-3}\right)$ & $1.76,-2.96$ \\
\hline
\end{tabular}

The ${ }^{13} \mathrm{C}$ CP-MAS-NMR spectrum was recorded, by use of cross-polarization from protons (contact time $5 \mathrm{~ms}$ ), on a Bruker DSX-300 spectrometer operating at $75.49 \mathrm{MHz}$ with a classical $4 \mathrm{~mm}$ probe head allowing spinning rates up to $10 \mathrm{kHz}$. The chemical shifts are given relative to tetramethylsilane. It was checked that there was a sufficient delay between the scans allowing a full relaxation of the nuclei.

\section{$2.3 X$-ray crystallographic study}

A single crystal was carefully selected under polarizing microscope in order to perform its structural analysis by X-ray diffraction. Diffraction data were collected on a Nonius Kappa diffractometer equipped with a CCD detector with graphite-monochromatized $\operatorname{MoK} \alpha$ radiation $(\lambda=0.71069 \AA)$. Intensities were corrected for Lorentz, polarization and absorption effects. ${ }^{9}$ The structure was solved by direct methods with the SIR97 suite of programs ${ }^{10}$ and refinement were performed on $F^{2}$ by full-matrix least-squares methods with all non-hydrogen atoms anisotropic. Hydrogens were included on calculated positions, riding on their carrier atoms, apart from those linked to OW1 and OW2, located in difference Fourier map, whose coordinates were kept fixed. $\mathrm{O} 2$ and $\mathrm{O} 3$ atoms of the nitrate groups have been found to be disordered over two equivalent positions. All calculations were performed using SHELXL-97 ${ }^{11}$ implemented in the WINGX system of programs. ${ }^{12}$ The crystal data are reported in table 1 . The drawings were made with Diamond ${ }^{13}$ and ORTEPIII. ${ }^{14}$

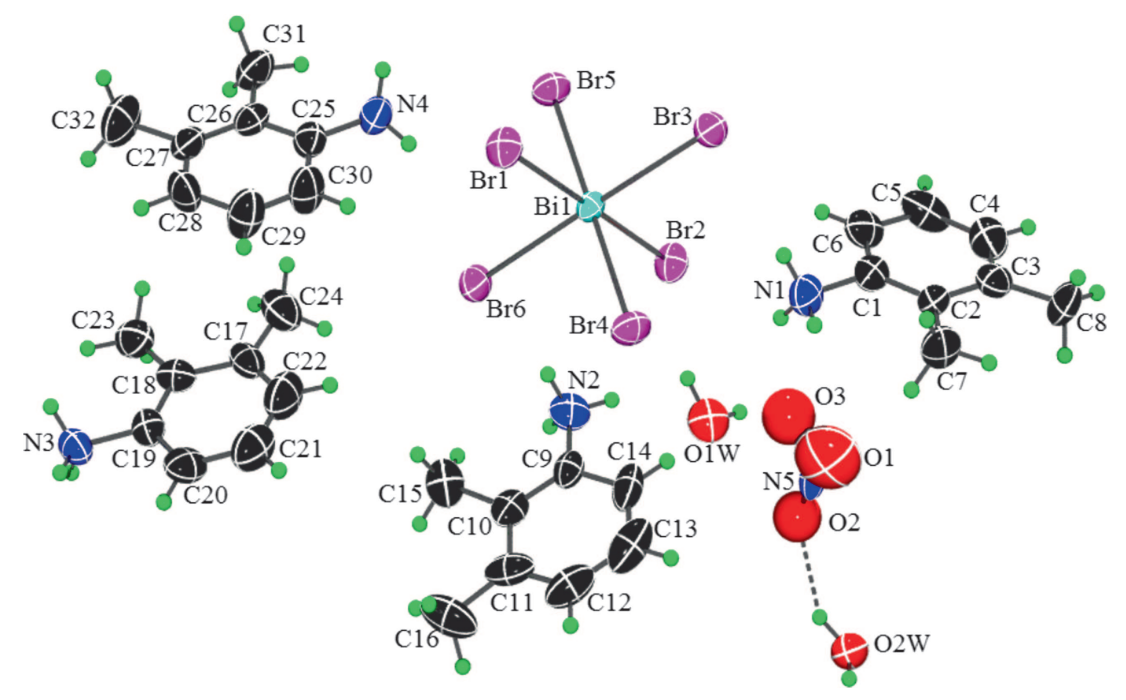

Figure 1. ORTEP view of $\left[2,3-\left(\mathrm{CH}_{3}\right)_{2} \mathrm{C}_{6} \mathrm{H}_{3} \mathrm{NH}_{3}\right]_{4} \mathrm{BiBr}_{6} \mathrm{NO}_{3} \cdot 2 \mathrm{H}_{2} \mathrm{O}$, showing the atom-labelling scheme. Displacement ellipsoids are drawn at the $50 \%$ probability level. Only one position of the disordered nitrate group is shown for clarity. 


\section{Results and Discussion}

\subsection{Description of the structure}

The crystal structure of $\left[2,3-\left(\mathrm{CH}_{3}\right)_{2} \mathrm{C}_{6} \mathrm{H}_{3} \mathrm{NH}_{3}\right]_{4} \mathrm{BiBr}_{6}$ $\mathrm{NO}_{3} .2 \mathrm{H}_{2} \mathrm{O}$ consists of isolated $\left[\mathrm{BiBr}_{6}\right]^{3-}$ and $\left[\mathrm{NO}_{3}\right]^{-}$ anions, four independent 2,3-dimethylanilinium cations and two crystallographically independent water molecules, as shown in figure 1 . The $\mathrm{Bi}$ atom is hexacoordinated to six $\mathrm{Br}$ atoms, in a slightly distorted octahedral geometry (table 2). The Bi-Br bond lengths are in perfect agreement with the mean value of 2.85(1) $\AA$ calculated on 16 CSD entries ${ }^{15}$ containing isolated $\mathrm{BiBr}_{6}$ complexes. The packing of the different molecular entities is shown in figure 2; the projection along the $b$ axis reveals a layered structure made of alternating inorganic and organic layers, linked trough weak N-H. . . Br and N-H. . O(water) hydrogen bonds (table 3). Almost all N-H and $\mathrm{O}-\mathrm{H}$ groups are involved

Table 2. Selected bond lengths and angles $\left(\AA{ }^{\circ}\right)$ for $[2,3$ $\left.\left(\mathrm{CH}_{3}\right)_{2} \mathrm{C}_{6} \mathrm{H}_{3} \mathrm{NH}_{3}\right]_{4} \mathrm{BiBr}_{6} \mathrm{NO}_{3} \cdot 2 \mathrm{H}_{2} \mathrm{O}$. E.s.d.'s are given in parentheses.

\begin{tabular}{lccc}
\hline Bi1 - Br1 & $2.870(1)$ & Bi1 - Br6 & $2.850(2)$ \\
Bi1 - Br2 & $2.865(1)$ & N1 - C1 & $1.46(2)$ \\
Bi1 - Br3 & $2.869(2)$ & N2 - C9 & $1.47(2)$ \\
Bi1 - Br4 & $2.834(1)$ & N3 - C19 & $1.47(2)$ \\
Bi1 - Br5 & $2.855(1)$ & & \\
Br1 - Bi1 - Br3 & $91.66(4)$ & Br2 - Bi1 - Br5 & $90.70(4)$ \\
Br1 - Bi1 - Br4 & $91.43(4)$ & Br2 - Bi1 - Br6 & $90.57(4)$ \\
Br1 - Bi1 - Br5 & $89.05(4)$ & Br3 - Bi1 - Br4 & $88.05(4)$ \\
Br1 - Bi1 - Br6 & $88.84(4)$ & Br3 - Bi1 - Br5 & $92.54(4)$ \\
Br2 - Bi1 - Br3 & $88.94(4)$ & Br4 - Bi1 - Br6 & $91.00(4)$ \\
Br2 - Bi1 - Br4 & $88.81(4)$ & Br5 - Bi1 - Br6 & $88.40(4)$ \\
\hline
\end{tabular}

in such hydrogen bonding interactions, which are often bifurcated. Inside the anionic layers, hydrogen bonds of O-H...O type are also established between water molecules and nitrate ions, as shown in figure 3. The presence of the $\left[\mathrm{NO}_{3}\right]$ anions in the anionic sublattice of the organic bismuthate family was already found in other structures. ${ }^{16}$

With regard to the organic cation arrangement, the organization of 2,3-dimethylanlinium groups, not in

Table 3. Selected bond lengths and angles $\left(\AA{ }^{\circ}\right)$ for $[2,3$ $\left.\left(\mathrm{CH}_{3}\right)_{2} \mathrm{C}_{6} \mathrm{H}_{3} \mathrm{NH}_{3}\right]_{4} \mathrm{BiBr}_{6} \mathrm{NO}_{3} \cdot 2 \mathrm{H}_{2} \mathrm{O}$. E.s.d.'s are given in parentheses.

\begin{tabular}{|c|c|c|c|c|}
\hline D-H...A & $\mathrm{d}(\mathrm{D}-\mathrm{H})$ & d(H...A) & d(D...A) & (DHA) \\
\hline N1-H2N. .O3A & 0.89 & 2.18 & $2.88(4)$ & 136 \\
\hline N1-H2N. . Br2 & 0.89 & 2.98 & $3.62(1)$ & 130 \\
\hline N1-H3N. ..Br3 & 0.89 & 2.72 & $3.60(1)$ & 171 \\
\hline N2-H4N. . Br6 & 0.89 & 2.53 & $3.41(1)$ & 169 \\
\hline N2-H5N. . Br4 ${ }^{\mathrm{a}}$ & 0.89 & 2.57 & $3.38(1)$ & 152 \\
\hline N2-H6N. . .O1W & 0.89 & 2.36 & $3.15(2)$ & 149 \\
\hline N3-H10N...Br3 ${ }^{b}$ & 0.89 & 2.61 & $3.39(1)$ & 146 \\
\hline N3-H11N...Br1 ${ }^{b}$ & 0.89 & 2.73 & $3.55(1)$ & 154 \\
\hline N3-H12N...Br5 ${ }^{c}$ & 0.89 & 2.46 & $3.34(1)$ & 171 \\
\hline N4-H7N. . Br1 & 0.89 & 2.99 & $3.70(1)$ & 138 \\
\hline N4-H7N. . Br6 & 0.89 & 3.00 & $3.70(1)$ & 138 \\
\hline N4-H8N. . .O1 ${ }^{\mathrm{d}}$ & 0.89 & 2.12 & $2.91(2)$ & 147 \\
\hline N4-H8N...O2A ${ }^{d}$ & 0.89 & 2.30 & $3.11(3)$ & 151 \\
\hline N4-H9N. .O22W & 0.89 & 2.08 & $2.90(2)$ & 152 \\
\hline $\mathrm{O} 2 \mathrm{~W}-\mathrm{H} 4 \mathrm{~W} \ldots \mathrm{O} 2$ & 0.90 & 2.09 & $2.91(3)$ & 150 \\
\hline $\mathrm{O} 2 \mathrm{~W}-\mathrm{H} 3 \mathrm{~W} \ldots \mathrm{Br} 1^{\mathrm{f}}$ & 0.91 & 2.88 & $3.54(1)$ & 131 \\
\hline O1W-H1W...Br3 & 0.92 & 2.73 & $3.40(1)$ & 131 \\
\hline O1W-H1W...Br2 ${ }^{g}$ & 0.92 & 2.88 & $3.60(1)$ & 136 \\
\hline
\end{tabular}

Symmetry codes: ${ }^{\mathrm{a}} \mathrm{x}, \mathrm{y}+1, \mathrm{z} ;{ }^{\mathrm{b}} \mathrm{x}-1,-\mathrm{y}+1, \mathrm{z}-1 / 2 ;{ }^{\mathrm{c}} \mathrm{x}-1,-\mathrm{y}+2$, $\mathrm{z}-1 / 2 ;{ }^{\mathrm{d}} \mathrm{x}-1 / 2,-\mathrm{y}+1, \mathrm{z} ;{ }^{\mathrm{e}} \mathrm{x}-1 / 2,-\mathrm{y}+2, \mathrm{z} ;{ }^{\mathrm{f}} \mathrm{x}+1 / 2,-\mathrm{y}+1, \mathrm{z}$; ${ }^{\mathrm{g}} \mathrm{x}, \mathrm{y}+1, \mathrm{z}$

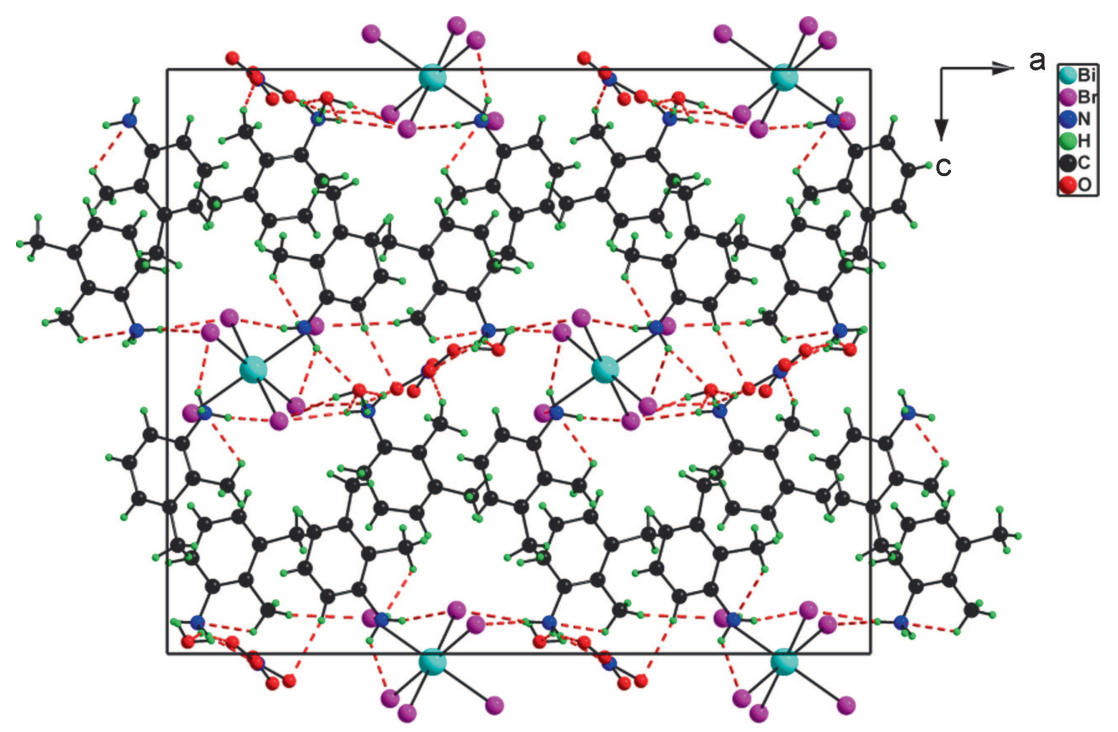

Figure 2. Projection of the crystal structure of $\left[2,3-\left(\mathrm{CH}_{3}\right)_{2} \mathrm{C}_{6} \mathrm{H}_{3} \mathrm{NH}_{3}\right]_{4}$ $\mathrm{BiBr}_{6} \mathrm{NO}_{3} \cdot 2 \mathrm{H}_{2} \mathrm{O}$ along the $b$-axis. The dotted lines indicate hydrogen bonds. 


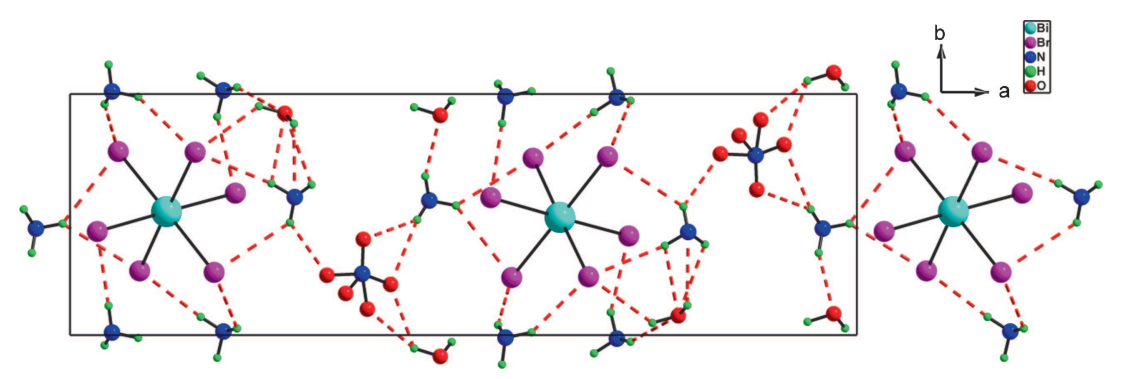

Figure 3. Projection of inorganic layer in the crystal structure of $\left[2,3-\left(\mathrm{CH}_{3}\right)_{2}\right.$ $\left.\mathrm{C}_{6} \mathrm{H}_{3} \mathrm{NH}_{3}\right]_{4} \mathrm{BiBr}_{6} \mathrm{NO}_{3} .2 \mathrm{H}_{2} \mathrm{O}$ along the $c$-axis.

opposition, is favourable to a non-centrosymmeric arrangement. ${ }^{17}$ The aromatic rings are all almost planar, with a maximum mean deviation of $0.0025 \AA$ from the calculated least-squared planes. Adjacent anilinium cations are approximately parallel to each other, but there is no $\pi-\pi$ stacking interactions among them since the centroid-to-centroid distances are found to be too large, being in the range of 4.605-4.616 $\AA .{ }^{18}$ The four 2,3-dimethylanilnium cations are differently connected to the anionic sublattice by weak N-H. . Br, N-H. . O hydrogen bonds (table 3 ). It is worthwhile to mention the important role of the water molecules in the cohesion of the atomic arrangement, which act both as proton donors (towards the nitrate anion) and as proton acceptors (from the anilinium cations).

\subsection{Infrared spectroscopy}

To gain more information on the crystal structure, we have recorded the IR spectrum of the title compound which is shown in figure 4 . The assignment of the internal modes of the organic cations is based on the

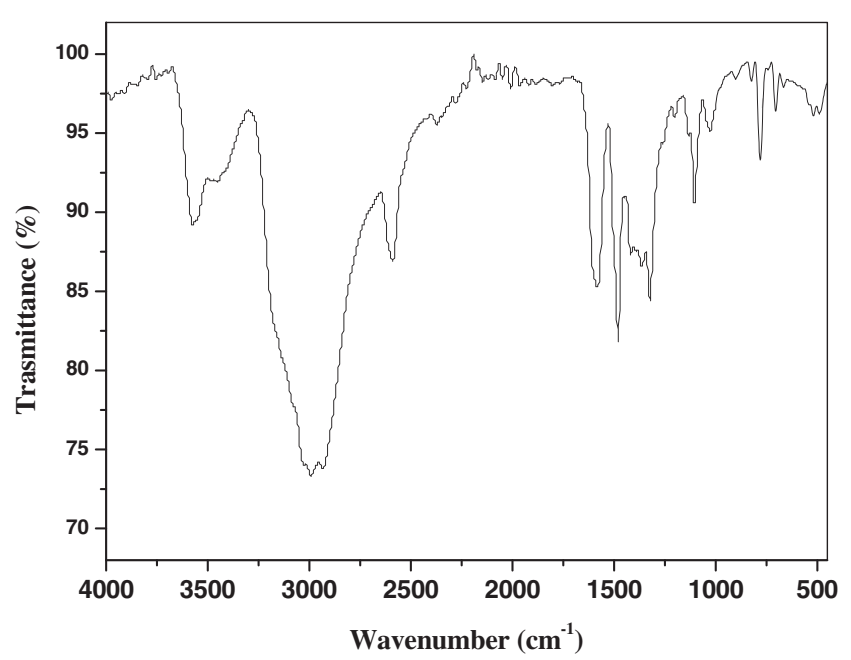

Figure 4. IR spectrum of $\left[2,3-\left(\mathrm{CH}_{3}\right)_{2} \mathrm{C}_{6} \mathrm{H}_{3} \mathrm{NH}_{3}\right]_{4} \mathrm{BiBr}_{6}$ $\mathrm{NO}_{3} \cdot 2 \mathrm{H}_{2} \mathrm{O}$. comparison with other compounds associated to the same cation and the literature data. ${ }^{17-19}$ The IR spectrum shows, at high wave numbers, the two broad bands at $3550-3450 \mathrm{~cm}^{-1}$ are attributed to $v(\mathrm{OH})$ of crystallization water molecules and $v\left(\mathrm{NH}_{3}^{+}\right)$, respectively. The broad bands in the range $3000-2920 \mathrm{~cm}^{-1}$ are attributed to $v(\mathrm{CH})$ and $v\left(\mathrm{CH}_{3}\right)$ stretching modes. The broad band at $1580 \mathrm{~cm}^{-1}$ is assigned to the stretching vibration of $\mathrm{C}=\mathrm{C}$ and to the bending modes of the $\mathrm{NH}_{3}$ and $\mathrm{OH}$ groups. The bands observed at 1480, 1420, 1464 and $1323 \mathrm{~cm}^{-1}$ correspond to the stretching vibrations of $\mathrm{C}=\mathrm{C}$ and $\mathrm{NO}_{3}$ anions. The weak bands at 1250, 1200 $\mathrm{cm}^{-1}$ and the moderate band centred at $1100 \mathrm{~cm}^{-1}$ are associated with the $v(\mathrm{C}-\mathrm{N})$ and $v(\mathrm{C}-\mathrm{C})$. The vibrations at $1025,899,829 \mathrm{~cm}^{-1}$ are caused by the $\delta(\mathrm{C}-\mathrm{H}), \delta(\mathrm{CC})$ of the aromatic ring and $\delta\left(\mathrm{NO}_{3}\right)$. The remaining bands in the range $780-485 \mathrm{~cm}^{-1}$ may be assigned to $\gamma(\mathrm{CCC})$, $\rho\left(\mathrm{NH}_{3}\right)$ and $\rho\left(\mathrm{NH}_{3}\right)$.

\subsection{NMR results}

Carbon signals are often broad and not always possible to distinguish between different carbons chemically very similar. The ${ }^{13} \mathrm{C}$ CP-MAS NMR spectrum of $\left[2,3-\left(\mathrm{CH}_{3}\right)_{2} \mathrm{C}_{6} \mathrm{H}_{3} \mathrm{NH}_{3}\right]_{4} \mathrm{BiBr}_{6} \mathrm{NO}_{3} .2 \mathrm{H}_{2} \mathrm{O}$ is shown in figure 5. It displays three peaks in the resonance region of the aliphatic carbon atoms, at 14.8, 15.6 and 19.9 $\mathrm{ppm}$. These resonances correspond to the carbon atoms of the eight crystallographically independent methyl groups. The first two peaks are assigned to the carbon atoms of the four crystallographically independent methyls in ortho position of the ammonium groups. The last peak is attributed to the carbon atoms of the four inequivalent methyls in meta position of the ammonium groups having very close chemical environments. The sum of the nine peaks with the chemical shifts spread between 121.1 and $139.7 \mathrm{ppm}$ is assigned to the carbon atoms of the four inequivalent aromatic rings of the title compound. The presence of only nine lines in this resonance region, due to the fact that some of crystallographically independent carbons have similar 

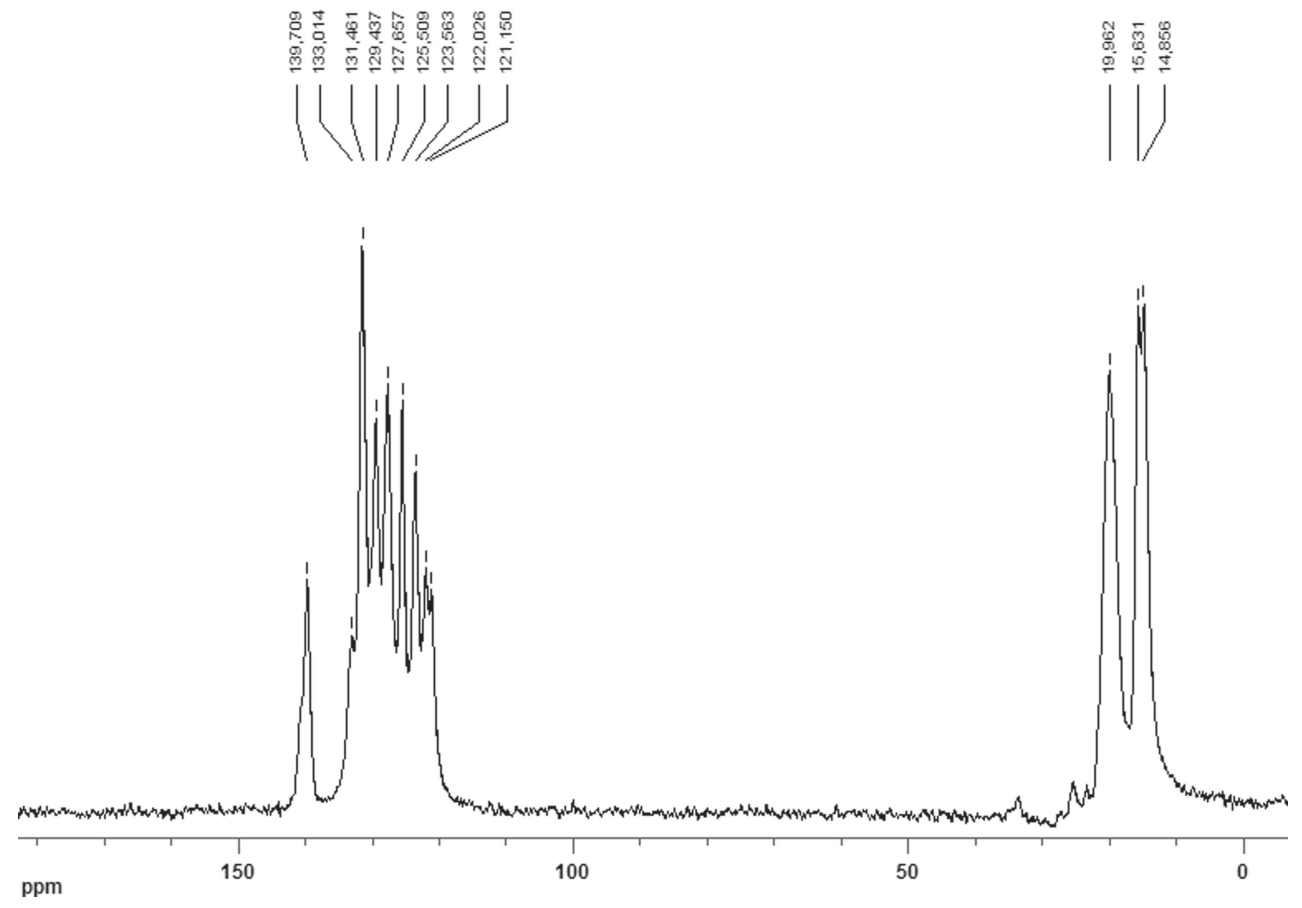

Figure 5. ${ }^{13} \mathrm{C}$ CP-MAS-NMR spectrum of $\left[2,3-\left(\mathrm{CH}_{3}\right)_{2} \mathrm{C}_{6} \mathrm{H}_{3} \mathrm{NH}_{3}\right]_{4} \mathrm{BiBr}_{6} \mathrm{NO}_{3} .2 \mathrm{H}_{2} \mathrm{O}$.

environments, proves that the asymmetric unit of the title compound contains more than one aromatic ring.

\section{Conclusion}

The crystallographic and spectroscopic studies have illustrated that $\left[2,3-\left(\mathrm{CH}_{3}\right)_{2} \mathrm{C}_{6} \mathrm{H}_{3} \mathrm{NH}_{3}\right]_{4} \mathrm{BiBr}_{6} \mathrm{NO}_{3} \cdot 2 \mathrm{H}_{2} \mathrm{O}$ crystallizes in the non-centrosymmetric space group $\mathrm{Pca} 2_{1}$ at room temperature. Its crystal structure can be described by alternation of organic and inorganic layers. The packing of this hybrid compound shows weak and moderate interlocking between the inorganic and organic entities by a multi-directional hydrogenbonding network. These interactions are known to exist in many systems of biological importance. The water molecules play an important role in stabilizing the structure by a set of intermolecular hydrogen bonds involving both $\mathrm{N}-\mathrm{H}$. . .O and O-H. . O types.

\section{Supplementary Information}

CCDC 1000448 contains the supplementary crystallographic data for this paper. These data can be obtained free of charge via www.ccdc.cam.ac.uk/conts/ retrieving.html (or from the Cambridge Crystallographic Data Centre, 12, Union Road, Cambridge, CB2 1EZ, UK (fax: +44 (1223) 336-033; e-mail: deposit@ccdc.cam.ac.uk).

\section{Acknowledgements}

This work was supported by the Tunisian Ministry of H. E. Sc. R.

\section{References}

1. (a) Maury O, Le Bozec H and Acc H 2005 Chem. Res. 38 691; (b) Green K A, Cifuentes M P, Samoc M and Humphrey M G 2011 Coord. Chem. Rev. 255 2530; (c) Evans O R, Lin W B and Acc H 2002 Chem. Res. 35 511

2. Chen C and Liu G 1986 Annu. Rev. Mater. Sci. 16203

3. Wang X Q, Xu D, Yuan D R, Tian Y P, Yu W T, Sun S Y, Yang Z H, Fang Q, Lu M K, Yan Y X, Meng F Q, Guo S Y, Zhang G H and Jiang M H 1999 Mat. Res. Bull. 34 2003

4. Marcy H O, Warren L F, Webb M S, Ebbers C A, Velsko S P, Kennedy G C and Catella G C 1992 App. Opt. 31 5051

5. Qin J G, Liu D Y, Dai C Y, Chen C T, Wu B C, Yang C L and Zhan C M 1999 Coord. Chem. Rev. 18823

6. Chaari N, Hamdi B, Chaabouni S and Zouari F 2007 $X$-ray Struct. Analysis $23 \times 183$

7. Ciapala P, Jakubas R, Bator G, Zaleski J, Pietraszko A, Drozd M and Baran J 1997 J. Phys. Condens. Matter. 9 627

8. Neve F, Francescangeli O and Crispini A 2002 Inorg. Chim. Acta. 33851

9. Blessing R H 1995 Acta Crystallogr. Sect. A $\mathbf{5 1} 33$

10. Altomare A, Burla M C, Camalli M, Cascarano G, Giacovazzo C, Guagliardi A, Moliterni A G, Polidori G and Spagna R 1999 J. Appl. Crystallogr. 32115 
11. Sheldrick G M 1997 SHELXL97Program for Crystal Structure Refinement University of Göttingen, Germany

12. Farrugia L J 1999 J. Appl. Crystallogr. 32837

13. Brandenburg K 1998 DIAMOND version 2.0

14. Burnett M N and Johnson C K 1996 ORTEPIII Report ORNL-6895, Oak Ridge National Laboratory, Oak Ridge, Tennessee, USA

15. Allen F H, Bellard S, Brice M D, Cartwright B A, Doubleday A, Higgs H, Hummelink T, HummelinkPeters B G, Kennard O, Motherwell W D S, Rodgers
J R and Watson D G 1979 Acta Crystallogr. B 35 2331

16. Golzar Hossa G M 2013 Acta Crystallogr. E 69 m402

17. Rayes A, Ben Nasr C and Rzaigui M 2004 Mat. Res. Bull. 391113

18. Janiak J 2000 J. Chem. Soc. Dalton Trans. 3885

19. Silverstein R M, Bassler G C and Morill T C 1974 In Spectrometric identification of organic compounds $3^{\text {rd }}$ Edition (New York: Wiley) 